\title{
An association between accessing lecture recordings, but not lecture attendance, and overall marks for optometry students in a pharmacology course
}

\section{Sheila Doggrell ( $\square$ sheila.doggrell@qut.edu.au ) \\ Queensland University of Technology}

\section{Research Article}

Keywords: Academic outcomes, Grades, Lecture attendance, Lecture recordings, Optometry students, Overall marks

Posted Date: December 9th, 2020

DOl: https://doi.org/10.21203/rs.3.rs-118346/v1

License: (9) This work is licensed under a Creative Commons Attribution 4.0 International License. Read Full License 


\section{Abstract}

Background: Most studies, in the absence and presence of lecture recordings, have shown that there is an association between lecture attendance and academic performance for students of the biological sciences, but it is not known whether this occurs when lecture attendance is low. The effect of accessing lecture recordings on academic outcomes is not clear. The aims were (i) to determine any association between lecture attendance and academic outcomes for students who had access to lecture recordings, (ii) to describe how students use lecture recordings, and (iii) to determine any association between accessing lecture recordings and academic outcomes.

Methods: During the lecture in week 1 and workshops in week 2, written consent was sought from the students to undertake the study. Lecture attendance and lecture recording access were measured. To determine whether there was an association between attending lectures or accessing lecture recordings and academic outcomes, Pearson's correlation coefficients were calculated.

Results: Consent was forthcoming from 48 students (75\%). The main findings in this study of lecture attendance and lecture recording access in second year undergraduate optometry students in a pharmacology course were (i) lecture attendance was very low (mean, 15\%), (ii) there was no association between lecture attendance and academic outcomes, (iii) early in semester, most of the accessing of lecture recordings was shortly after the lecture was presented, whereas later in the semester, most of the accessing was prior to the examination, and (iv) there was a significant weak association between accessing lecture recordings and academic outcomes.

Conclusions: It is possible that as lecture attendance decreases and students become more reliant on lecture recordings, the positive association between lecture attendance and academic outcomes is lost, and a positive association between accessing lecture recordings and academic outcomes emerges.

\section{Background}

The first identified predictors of academic outcomes at university were prior academic performance and study skills [1]. Subsequently, other predictors have been identified including psychological predictors (e.g. commitment and satisfaction with university), cognitive appraisal, demographics (e.g. employment responsibilities, student workload [1] and attending lectures [2]. However, accessing lecture recordings (slides with audio) has not been established as a factor predicting academic performance at university.

In a recent systematic review of the association of lecture attendance and academic performance, it was shown that for students studying the human biosciences, in 24 of 32 courses (75\%) there was a positive association [3]. When the studies were divided into those reporting or not reporting the use of lecture recordings, 11 of the 16 courses (69\%) and 13 of 16 courses (82\%), respectively, showed a positive association [3]. One limitation to this review, is that when studies do not report the availability of lecture recordings, it does not equate to recordings not being available. Nevertheless, presently, there is no 
definitive evidence that the availability of lecture recordings alters the positive association between lecture attendance and academic outcomes.

Lecture attendance relating lecture attendance to academic outcomes in the biological sciences was often high in studies reported before or in 2015), [4-10]. However, the increasing use of technology, especially the availability of lecture recordings, probably reduces lecture attendance $[11,12]$. This is supported by recent studies; (i) a 2018 study showing lecture attendance of $24 \%$ in two courses [13], (ii) a 2019 study showing that the attendance at hybrid lectures declined over three years from 79-22\% [14], and (iii) at QUT, attendance at lectures by medical laboratory science students declined from $39 \%$ in 2017 to $27 \%$ in 2018 [15]. With the use of lecture recordings, students with low lecture attendance may have improved academic outcomes, compared to when lecture recordings were not available. This may negate any positive association between lecture attendance and academic outcomes.

Most of the quantitative data available about how students access lecture recordings is from questionnaires/surveys and much of it is for students studying the biological sciences. In general, students only accessed about $50-75 \%$ of available lecture recordings, and most accesses were only to parts of the recording [16-18]. Although student surveys give useful information on lecture recording access, student recall of how they access lecture recording may not be accurate, and direct access data will give more accurate findings. For instance, access data has shown that lecture recordings were accessed by $65 \%$ of biology and 'spikes' in viewing occurred prior to tests [19].

For students of biological sciences, who have access to face-to-face lectures, studies of any association between the use of lecture recordings and academic outcomes have given mixed results. Most studies have shown no association between accessing lecture recordings and academic performance $[11,15,16$, 19-22]. Other studies have shown that the use of lecture recordings to be negatively $[17,23-25]$ or positively [19] associated with academic outcomes.

For optometry students who have access to lecture recordings, there are no studies of whether there is any association between attending lectures or accessing lecture recordings and academic outcomes in the biological sciences. For students studying pharmacology, studies have not considered direct data of how students access lecture recordings on a weekly or ongoing basis. It is also not known whether there is any association between accessing lecture recording and academic outcomes for optometry students. In the present study, participants were second year undergraduate optometry students studying pharmacology. The first aim of this study was to determine any association between lecture attendance and academic outcomes for students who had access to lecture recordings. This was to test the hypothesis that, when lecture recordings are available, and lecture attendance is low, there is no association between lecture attendance and academic outcomes. The second aim was to describe how students use lecture recordings. The hypothesis was that most students who used recordings would access them in the week after lecture delivery and again/or prior to examinations. The third aim was to determine any association between accessing lecture recordings and academic outcomes to test the 
hypothesis that there is a positive association between accessing lecture recordings and academic outcomes.

\section{Methods}

The Bachelor of Vision Science degree at Queensland University of Technology (QUT) is a pre-requisite to the Masters of the Master of Optometry, which allows students to practise as optometrists. As part of the Vision Science program, a Foundations of Pharmacology course is undertaken. It is a second-year level, 12 credit point course ( 96 credits/year is full-time study). The course had 2 hours of lecturing/week over 10 weeks, which were made available via Blackboard as recordings (Echo 360; voice and lecture slides/PowerPoints). The course was supported by a weekly two-hour workshop, where students worked through worksheets, which related to the previous lecture and were made available prior to the workshop via Blackboard. At the workshop, students were supported by tutors. The marks were $50 \%$ for the examination, which is a mixture of multiple-choice questions and short answer questions, restricted to lecture content, and $50 \%$ for ongoing assessment. The ongoing assessment was not related to the lecture content and was $30 \%$ for a seminar presentation of a research article at a workshop, and $20 \%$ for a case study of drug interactions involving eye medicines. There were no marks for the worksheets completed in workshops.

The author was not involved in any aspect of the running or teaching of the Foundations of Pharmacology course. Most of the methods used in this study have been described in detail previously [3]. Ethical approvals for this research were obtained from the Human Research Ethics Committee at Queensland University of Technology; Ethics Approval Number 1700000690. During the lecture in week 1 and workshops in week 2, written informed consent was sought from the students by the author to undertake the study.

For the attendance part of the study, the students were asked to consent to sign an attendance register at each lecture, and for permission to link this data to their academic outcomes. A list of students who had consented to participate was prepared, and then circulated at the lectures from week 2 onwards, to allow attending students to sign.

For the lecture recording part of the study, the students were asked to consent to their lecture recording access data being collected and related to their academic outcomes. Lecture recordings at our university are made available shortly after the face-to-face lecture and can be accessed by students directly from the course Blackboard site or after downloading the recordings. Data for the recordings are only available to the course lecturer or others approved by the course coordinator and the manager of student support and curriculum. This approval was sought by the author and obtained. Data is only available for students that are accessed the recordings via Blackboard. The lecture was presented on Monday, 5-7 pm, and the number and duration of accesses was obtained on the Friday following the lecture, and then weekly throughout the semester for each lecture. In addition, the overall access to lecture recordings was the cumulative access at the time of the final examination. 
Like most Australian universities, passing grades at QUT are 4 (overall mark, 50-64\%), 5 (65-74\%), 6 $(75-84 \%)$ and 7 ( $\geq 85 \%)$. Academic outcomes measured were the grade, overall mark, marks for the examination, and for the ongoing assessment.

\section{Statistics}

From the attendance list, the percentage of attending students/week was determined and averaged, and for each consenting student, the number of lectures attended was collated. Percentage attendance of students in weeks 2-3 and weeks 6-10 were compared by Student's paired t-test. Grades, overall mark, and marks for the individual components were totalled and the total expressed as a percentage. Marks for the exam, seminar presentation and case study were compared by Students paired t-test. Mean values for percentage attendance and academic outcomes (grade, overall mark, examination, ongoing assessment) \pm standard deviation (SD) were determined.

The percentage of consenting who accessed each lecture on Blackboard was determined. Means \pm standard deviation (SD) were determined for (i) overall percentage of students accessing lecture recordings (ii) the number of times each student accessed each lecture recording and (iii) the number and percentage of lectures accessed/student.

Regression line analysis of academic outcomes vs lecture attendance or lecture recording access was undertaken. Pearson's correlation coefficient ( $r$ ) and significance (F/P values) were calculated using the regression tool in the data analysis function of Microsoft Excel to determine whether there was an association between the two variables; attending lectures or accessing lecture recordings and academic outcomes. Correlation coefficients of $0-0.19$ were considered as very weak, $0.2-0.39$ weak, $0.4-0.59$ moderate, $0.6-0.79$ strong, $0.8-1.0$ very strong:

http://www.statstutor.ac.uk/resources/uploaded/pearsons.pdf .

\section{Results}

The research was undertaken in semester 2 of 2019. At the start of semester, 64 optometry students were enrolled in the pharmacology course. Consent was forthcoming from 48 students (75\%). One student did not complete, and one student failed (overall mark, $46 \%$ ).

\section{Academic outcomes}

Overall marks and grades were high (Table 1). Marks for the ongoing assessment (seminar presentation and case study) were significantly higher than for the exam (Table 1). 
Table 1

Academic outcomes

\begin{tabular}{|c|c|}
\hline Academic outcome & $\begin{array}{l}\text { Mark } \\
(n=47)\end{array}$ \\
\hline Grade & $5.9 \pm 1.1$ \\
\hline Overall mark & $79 \% \pm 12$ \\
\hline Seminar presentation & $88 \% \pm 4^{\star}$ \\
\hline Case study & $85 \% \pm 14^{*}$ \\
\hline Exam & $71 \% \pm 20$ \\
\hline \multicolumn{2}{|c|}{ * Significantly different $(P<0.01)$ with exam mark by Students paired t-tes } \\
\hline
\end{tabular}

\section{Lecture attendance and academic outcomes}

Percentage attendance was not measured in week 1 , as this was prior to the consent collecting process. The average percentage lecture attendance for completing students was $15 \% \pm 33$ (47) over the semester. Attendance was higher at the start of the semester than later (Fig. 1); weeks $2-3 ; 28 \% \pm 41$ (47) vs weeks $6-10 ; 16 \% \pm 32$ (47), $P=0.004$ by Student's paired t-test.

Regression line analysis of grades and marks versus lecture attendance showed no associations (Table 2). As a previous study had shown that a failing student can skew the regression line analysis and association between lecture attendance [25], the analysis was repeated without the failing student, and this analysis also showed no association between lecture attendance and academic outcomes (data not shown).

Table 2

Regression analysis of academic outcomes vs lecture attendance or accessing lecture recordings

\begin{tabular}{|lllllll|}
\hline $\begin{array}{l}\text { Academic } \\
\text { outcome }\end{array}$ & $\begin{array}{l}\text { Lecture } \\
\text { attendance }\end{array}$ & $\begin{array}{l}\text { No of lecture recordings } \\
\text { accessed }\end{array}$ & $\begin{array}{l}\text { \% of lecture recording } \\
\text { accessed }\end{array}$ & \\
\cline { 2 - 4 } & $\begin{array}{l}\text { Pearson's } \\
\mathbf{r}\end{array}$ & $\begin{array}{l}\boldsymbol{P} \\
\text { value }\end{array}$ & Pearson's r & Pvalue & Pearson's r & Pvalue \\
\hline Grade & 0.110 & 0.46 & 0.382 & 0.008 & 0.387 & 0.007 \\
\hline Overall mark & 0.217 & 0.14 & 0.329 & 0.023 & 0.327 & 0.025 \\
\hline $\begin{array}{l}\text { Seminar } \\
\text { presentation }\end{array}$ & 0.174 & 0.24 & 0.095 & 0.525 & 0.132 & 0.375 \\
\hline Case study & 0.152 & 0.31 & 0.151 & 0.311 & 0.108 & 0.469 \\
\hline Exam & 0.152 & 0.31 & 0.335 & 0.021 & 0.347 & 0.017 \\
\hline
\end{tabular}


The students in this course had two ways of accessing lecture recordings. They could access them directly on Blackboard where access is immediate, or they can download the lecture recording to a personal device before accessing, and this is a slow process. The university only has information about lecture recordings accessed from Blackboard, not from recordings accessed after downloading. Thus, the following data is limited to students who accessed lecture recordings via Blackboard. There were 43 of the 48 consenting students who did this, which is $90 \%$ of the consenting students.

Prior to the final examination, the students had 102 days in which to access the lecture recordings for lecture 1 , which declined to 37 days for lecture 10 . The average running time of a lecture recording was $91 \pm 27$ (10) minutes.

\section{Accessing lecture recordings}

Of the 43 consenting student who accessed lecture recordings on Blackboard, six only accessed one recording, and six accessed all 10 recordings. There were two distinct patterns of how the students accessed the lecture recordings: for lectures $1-3$, most of the accessing was in the first three weeks after the lecture was presented, whereas for lectures 4-10 most of the accessing was in the three weeks prior to the examination (Fig. 2).

The average number of students viewing each lecture was $21.9 \pm 3.7$ (47), and the mean percentage viewed was $36.5 \% \pm 33.7$ ( 47 , range $0-100 \%)$ of each lecture. For those students who accessed lecture recordings, the number of lecture recordings accessed/student during the semester was $5.3 \pm 3.3$ (43). Most of the students did not access the recordings in their entirety in one access, and the average number of accesses/lecture recording was $2.2 \pm 1.6$ (43); range $1-7$.

\section{Lecture recording access and academic outcomes}

Regression line analysis showed that there were significant weak positive associations between grades or overall marks and number of lecture recordings accessed/student (Table 2). This association was predominantly due to a significant association between the examination marks and lecture recordings accessed (Table 2). There was no association between the marks for the seminar presentation or case study and accessing lecture recordings (Table 2). There were similar findings when the average percentage of each lecture recording accessed/student was used as a measure of lecture recording access in the regression analysis (Table 2).

\section{Discussion}

The main findings in this study of lecture attendance and lecture recording access in second year undergraduate optometry students in a pharmacology course were (i) lecture attendance was very low, (ii) there was no association between lecture attendance and academic outcomes, (iii) early in semester, most of the accessing of lecture recordings was shortly after the lecture was presented, whereas later in semester, most of the accessing was prior to the examination, and (iv) there was a significant weak association between accessing lecture recordings and academic outcomes. 


\section{Lecture attendance}

Lecture attendance reported in previous studies relating lecture attendance to academic outcomes in the biological sciences was often high: $79 \%$ [4] or $91 \%$ [10] of students attending all lectures, $90 \%$ of students attending $\geq 70 \%$ of lectures [5], $88 \%$ of students attending $\geq 56 \%$ of lectures [7], average attendance was $73 \%$ [8] or ranged from $20-90 \%$ in four courses [9] or from $58-95 \%$ in six courses [6]. However, with the increasing availability of lecture recordings, lecture attendance may be declining (see Introduction). In the present study, the average percentage lecture attendance/student was $15 \%$ in 2019 , which fits in with a recent decline in lecture attendance.

\section{Lecture attendance and academic outcomes}

In the present study, where lecture recordings were available to the students, it was shown lecture attendance was not associated with better academic outcomes for optometry students in a pharmacology course, with the availability of lecture recordings. This is supported by some but not all previous studies. Previous studies students in the biological sciences with access to lecture recordings, have either shown no association between lecture attendance and academic outcomes $([3,10,13,27,28]$ three of four courses [9]) or a positive association $([4,5,7,8,26,29]$ one course of four studied [9]) has been reported.

For human bioscience students, the availability of lecture recordings could reduce the likelihood of there being a positive association between lecture attendance and academic outcomes. However, in a recent systematic review of the association of lecture attendance and academic performance, it was shown that for students studying the human biosciences, there was no difference in the percentage of studies reporting a positive association between studies that reported, or did not report, the availability of lecture recordings [3]. One limitation to this review, is that when studies do not report the availability of lecture recordings, it does not equate to recordings not being available. Nevertheless, to date, there is no definitive evidence that the availability of lecture recordings alters the positive association between lecture attendance and academic outcomes.

Attendance levels are a possible reason for the differences between this study showing no association between lecture attendance and academic outcomes and previous studies showing a positive association is that this study is considering the relationship of much lower levels of lecture attendance to academic outcomes than most previous studies. Other studies with low levels of lecture attendance, and the availability of lecture recordings (39\% [27], 24\% [13], 27\% [15]), have also shown no association between lecture attendance and academic outcomes. This supports the study hypothesis that, when lecture recordings are available, and lecture attendance is low, there is no association between lecture attendance and academic outcomes.

\section{How students access lecture recordings}

The pattern of how students accessed lecture recordings in the present study has similarities and differences to previous reports. The similarities were that only about half of the students accessed the 
recordings, and access to each recording often involved more than one access, but access was not usually to the whole lecture [16-18]. A previous study has reported 'spikes' in accessing lecture recordings prior to tests [19]. The differences between the present and previous studies were probably related to only having one, a final examination, in the present course, and thus, there were not recurring spikes. Having only one examination seems to have created two patterns of accessing lecture recordings; for lectures 1-3, most of the accessing was in the first three weeks after the lecture was presented, with little evidence of accessing or re-accessing prior to the exam, whereas for lectures 4-10 most of the accessing was in the three weeks prior to the examination, and was increasing at the time of the examination. As accessing was still increasing at the time of the examination, some students may not have completed their preparation for the examination. Thus, consideration needs to be given on how to persuade students to access lecture recordings in a timelier way. One approach maybe to introduce weekly quizzes requiring information from the lecture.

\section{Associations between lecture recording access and academic outcomes}

We have shown weak positive associations between accessing lecture recordings and grades, overall marks and the examination marks, but not for marks in the seminar presentation and case study, for students in a pharmacology course. As the seminar presentation and case study were not related to lecture content, the finding of no association with accessing lecture recordings is as expected. The finding of an association between accessing lecture recording and academic outcomes involving lecture content is not in line with most previous studies. Thus, most previous studies of students of the biological sciences have shown no association between accessing lecture recordings and academic performance $[6,11,15,16,19,21,22]$, or a negative association $[17,23,24]$.

One possible reason for the difference between our finding of a weak positive and previous findings of no or negative associations between accessing lecture recordings and academic outcomes is that we are studying optometry students. Optometry students have not been studied previously and may be different in how they use the lecture recordings than other students.

The difference between this and previous studies is unlikely to be due to the discipline being studied as the optometry students were studying pharmacology. A previous study of biomedical science students studying pharmacology showed no association between accessing lecture recordings and academic outcomes, when failing students were removed from the analysis [25], as was done in the present study.

A major difference between the present and previous studies considering the relationship between accessing lecture recordings and academic outcomes is that lecture attendance was much lower in this study than previous studies. Thus, there may be a change in the way students learn from being reliant on face-to-face lectures to being more reliant on other resources, such as accessing lecture recordings.

A recent study supports the present finding by showing a positive association between accessing online resources and academic outcomes for nursing students undertaking a course in anatomy, physiology and 
microbiology [30]. However, this study was different to ours, as the nursing students also had access to other online resources i.e. concept clips and an interactive anatomy atlas. These other resources may have contributed to the positive association between the access to lecture recordings and academic outcomes [30].

\section{Limitations}

A limitation to this study is that it is a relatively small study of 64 optometry students studying pharmacology. A second limitation is that the introduction and discussion are limited to students studying biological sciences, and these findings may differ from those of students studying other disciplines. A third limitation to the study is that only some of resources available to the students were studied (lecture attendance and lecture recording access) and the use of other resources (e.g. workshops) may have contributed to the academic outcomes.

\section{Abbreviations}

Queensland University of Technology, QUT; student numbers (IDs); Pearson's correlation coefficients ( $r$ values); standard deviation of mean, SD

\section{Declarations}

\section{Ethics approval and consent to participate request}

Ethical approval for this research were obtained from the Human Research Ethics Committee at Queensland University of Technology; Ethics Approval Number 1700000690. All methods were performed in accordance with the guidelines and regulations imposed in the ethical approval.

\section{Consent for publication:}

Manuscript does not have details relating to individuals.

\section{Competing interests:}

No competing interests

\section{Funding:}

None

\section{Author's contribution:}


SAD is the sole author and was responsible for the conception and design of the work, acquisition, analysis and interpretation of data, and writing of the manuscript. SAD is the only writer of the submitted version and has approved submission and is personally accountable for it. SAD is the corresponding author.

\section{Acknowledgements:}

Peter Molenaar, who was the course coordinator, and sole academic involved in the teaching of the medical laboratory course, for allowing me access to his students to undertake this study.

\section{References}

1. McKenzie K, Schweitzer RD. Who succeeds at university? Factors predicting academic performance in first year Australian university students. Higher Educ Res \& Dev 2001;20:21-33.

2. Credé M, Roch SG, Kieszczynka UM. Class attendance in college: a meta-analytic review of the association of class attendance with grades and student characteristics. Rev Educ Res 2010;80:272.

3. Doggrell SA. A systematic review of the relationship between lecture attendance and academic outcomes of students studying the human biosciences. Int J Innovation Sci Math Educ 2020;28:6076.

4. Fernandes L, Maley M, Cruickshank $C$. The impact of online lecture recordings on learning outcomes in Pharmacology. J Int Assess Med Sci Educ 2008;18:2.

5. Soto JG, Anand S. Factors influencing academic performance of students enrolled in a lower division cell biology core course. J Scholar Teach Learn 2009;9:64-80.

6. Bollmeir SG, Wenger PJ, Forinash AB. Impact of online lecture-capture on student outcomes in a therapeutics course. Am Pharm Educ 2010;74:127.

7. Hidayat L, Vansal S, Kim E, Sullivan M, Dalbu R. Pharmacy student absenteeism and academic performance. Amer J Pharmac Educ 2012;76:1-6.

8. Horton DM, Widerman SD, Saint DA. Assessment outcome is weakly correlated with lecture attendance: influence of learning style and use of alternative materials. Adv Physiol Educ 2012;36:108-15.

9. Davis EA, Hodgson Y, Macaulay JO. Engagement of students with lectures in biochemistry and pharmacology. Biochem Mol Biol Educ 2012;40:300-9.

10. Selvig D, Holaday LW, Purkiss J, Hortsch M. Correlating students' educational background, study habits, and resource usage with learning success in medical histology. Anat Sci Educ 2015;8:1-11.

11. Edwards MR, Clinton ME. A study exploring the impact of lecture capture availability and lecture capture usage on student attendance and attainment. High Educ 2019;77:403-21.

12. Traphagan T, Kucsera JV, Kyoko K. Impact of class lecture webcasting on attendance and learning. Educ Technol Res Dev 2010;58:19-37. 
13. Kauffman CA, Derazin M, Asmar A, Kibble JD. Relationship between classroom attendance and examination performance in a second-year medical pathophysiology class. Adv Physiol Educ 2018;42:592-8.

14. Al Khaja KAM, Tayem Y, James H, Jaradat A, Sequeira RP. Pharmacology and therapeutics resource session attendance and academic performance of pre-clerkship medical students if a problem-based learning curricula. BMC Med Educ 2019;19:269.

15. Doggrell SA. No apparent association between lecture attendance or accessing lecture recordings and academic achievement in a medical laboratory course. BMC Med Edu 2020;20:207.

16. Leadbeater W, Shuttleworth T, Couperthwaite J, Nightingale KP. Evaluating the use and impact of lecture recording in undergraduates: Evidence for distinct approaches by different groups of students. Comput Educ 2013;61:185-92.

17. Simcock DC, Chua WH, Hekman M, Levin MT, Brow, S. A survey of first-year biology student opinions regarding live lectures and recorded lectures as learning tools. Adv Physiol Educ 2017;41;69-76.

18. Groen JF, Quigley B, Herry Y. Examining the use of lecture capture technology: implications for teaching and learning. CJSoTL 2016;7:n1.

19. Williams AE, Aquilar-Roca NM, O’Dowd DK. Lecture capture podcasts: differential student use and performance in a large introductory course. Educ Tech Research Dev 2016;64:1-12.

20. Solomon DJ, Ferenchick GS, Laird-Fick HS, Kavanaugh K. A randomized trial comparing digital and live lecture formats [ISRCTN40455708]. BMC Med Educ 2004;4:27.

21. Bacro TR, Gebregziabher M, Fitzharris TP. Evaluation of a lecture recording system in a medical curriculum. Anat Sci Educ 2010;3:300-8.

22. Franklin DS, Gibson JW, Samuel JC, Teeter WA, Clarkson CW. Use of lecture recordings in medical education. Med Sci Educ 2011;1:21-9.

23. McNulty JA, Hoyt A, Gruener G, Chandrasekhar A, Espiritu B, Price Jr R, Naheedy R. An analysis of lecture video utilization in undergraduate medical education: associations with performance in the courses. BMC Med Educ 2009; 9:6.

24. Johnston ANB, Massa H, Burne THJ. Digital lecture recording: a cautionary tale. Nurse Educ Pract 2013;13:40-7.

25. Doggrell SA. The relationships between lecture attendance or accessing lecture recordings and academic outcomes: results for a pharmacology course in a biomedical science degree. Int J Innovation Sci Math Educ 2019;27:1-12.

26. Doggrell SA. Does attending lectures matter when lecture recordings are available? Results for a preliminary study comparing attending and non-attending nursing students in bioscience and pharmacology. Int J Innovation Sci Math Educ 2018;26:1-10.

27. Eisen DB, Schupp CW, Isseroff RR, Ibrahimi OA, Ledo L, Armstrong AW. Does class attendance matter? Results from a second-year medical dermatology cohort study. Int J Dermatol 2015;54:80716. 
28. Azab E, Saksena Y, Alganem T, Midle JB, Molgaard K, Albright S, Karimbux N. Relationship among dental students' class lecture attendance, use of online resources, and performance. J Dent Educ 2016;80:4 2-8.

29. Popovic N, Popovic T, Dragovic IR, Cmiljanic O. A Moodle-based blended learn solution for physiology education in Montenegro: a case study. Adv Physiol Educ 2018;42:111-7.

30. Guy R, Byrne B, Dobos M. Optional anatomy and physiology e-learning resources: student access, learning approaches, and academic outcomes. Adv Physiol Educ 2018;42:43-9.

\section{Figures}

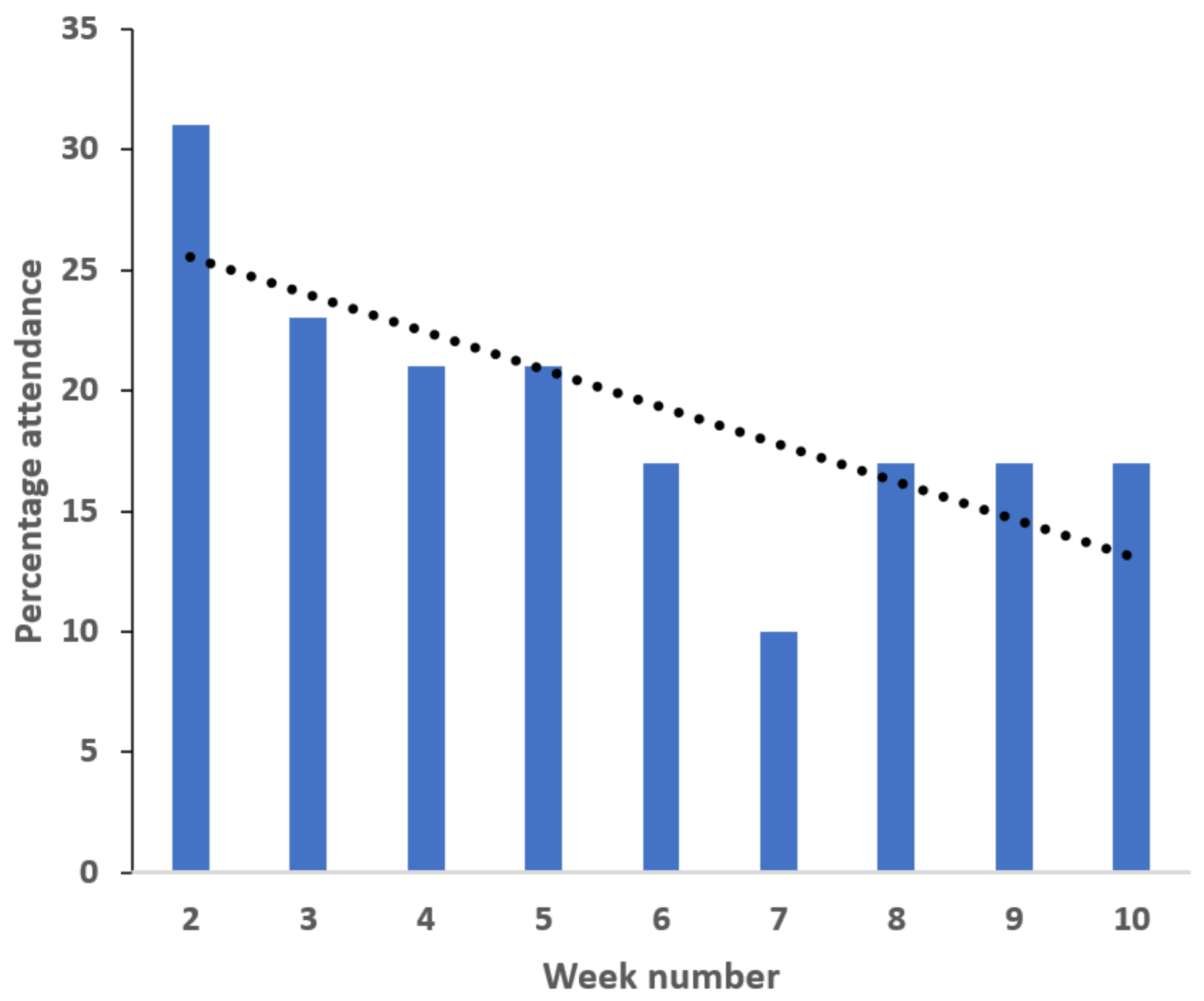

Figure 1

Percentage attendance versus week number with trendline fitted. 


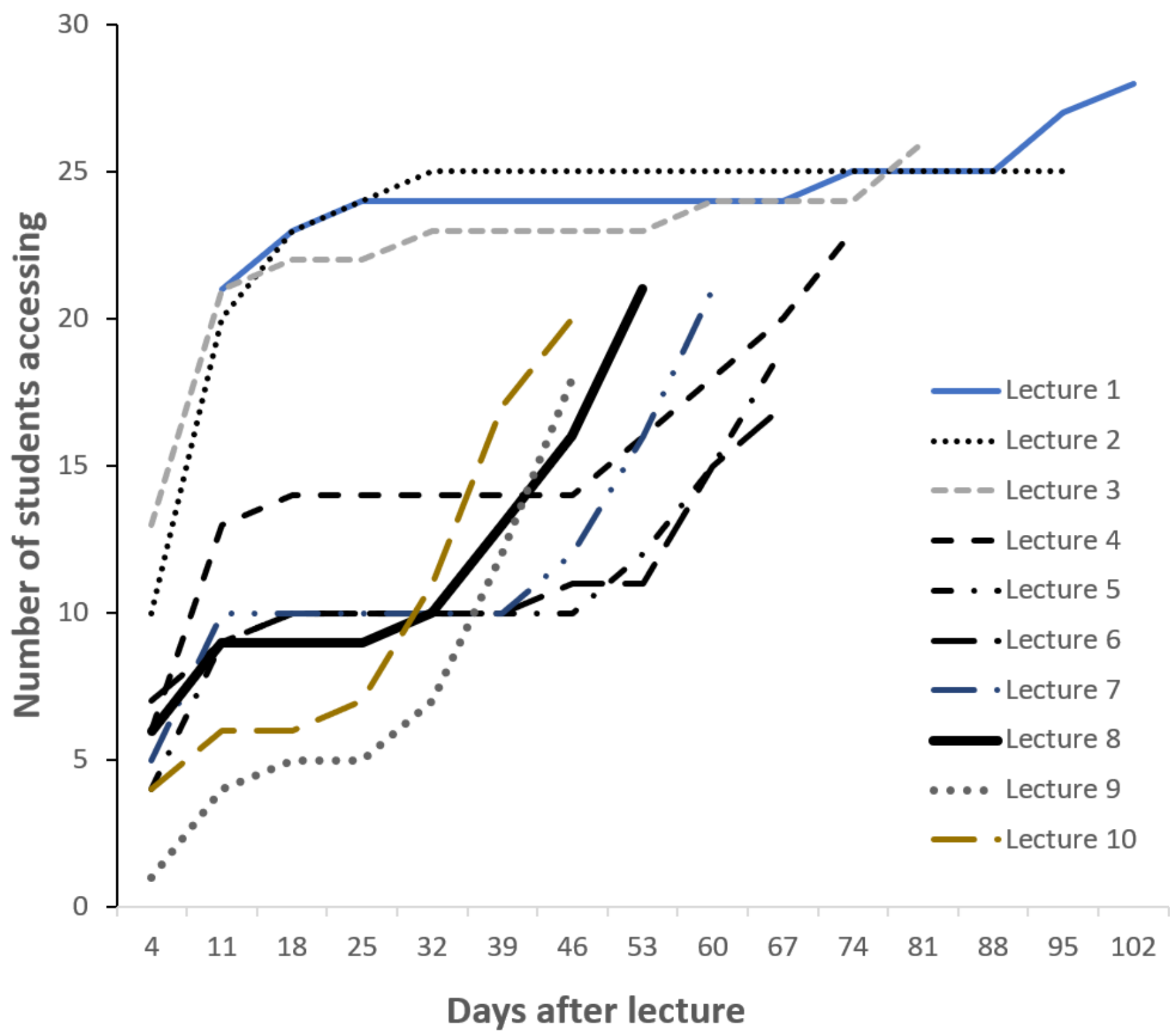

Figure 2

Number of students accessing lectures plotted against day after lecture 